\title{
A Smart Eye for the Lost Aeroplane
}

\author{
P.Chitra, M.Sumathi, A.Sahaya Anselin Nisha, R.Sakthi Prabha, G.Jegan
}

\begin{abstract}
Now a days even with the aeronautical modern technology along with weather forecasting, aviation accidents still cannot be avoided and hearing news about loss of control, airplane crashes and disappearance due to humans errors, bad climate, mechanical failure or any obstruct. Some missing flights in middle of the seas still could not found where they were collapsing. In this paper the design of a module consists of two layers inner and outer with some sensors. The module is made with hard metal, whenever the flight crashes and interact with water the $\mathrm{pH}$ sensor will measure the water. If the water salinity is equal to the sea water, the outer layer of the module become open up and using GPS can find current location and transmitted through RF transmitter. In case of some regions like Bermuda triangle no signals work.The inner module that designed the body like, does not allow the water to pass through it easily inside and it can float on the water. The module consists of high intensity flickering lights can easily identify the location where the module present and through memory in the module can find the place where the planes were collapsed..
\end{abstract}

Keywords : GPS, LoRa, mpu6050, vibration sensor, pH sensor, Solenoids.

\section{INTRODUCTION}

There were three major commercial airplane. Accidents were occur throughout the year of 2014. First, MH370 that reported lost on March $8^{\text {th }} 2014$ is still unfound at the time of the writing [1]. CNN reveals that the airplane was just entering the South China Ocean when it lost contact with the command center. After the incident, the rescue and search operations from multiple countries are conducted but still unsuccessful in locating the airplane. The final data indicates that the airplane has changed its altitude ad direction away from the planned course. In another incident, MH17 was shot down on July $17^{\text {th }} 2014$ and was found on the earth moments later [2]. QZ8501 was reported lost on December $28^{\text {th }} 2014$ and found after 6 days in the Java Sea. According to CNN international, there was no mental tension call made by the airplane when it lost contact. After one and an half hour the airplane was declared as lost, the search operation was initiated. Initially, there were no sign of wreckage and signals to pinpoint the airplane location around the last contacted

Revised Manuscript Received on December 30, 2019.

* Correspondence Author

P.Chitra*, School of electrical and electronics, Sathyabama institute of science and technology, Chennai, India.

E-mail chitraperumal@gmail.com

M.Sumathi, School of electrical and electronics, Sathyabama institute of science and technology, Chennai, India.

E-mail chitraperumal@gmail.com

A.Sahaya Anselin Nisha, School of electrical and electronics, Sathyabama institute of science and technology, Chennai, India.

R.Sakthi Prabha, School of electrical and electronics, Sathyabama institute of science and technology, Chennai, India.

G.Jegan, School of electrical and electronics, Sathyabama institute of science and technology, Chennai, India.

(C) The Authors. Published by Blue Eyes Intelligence Engineering and Sciences Publication (BEIESP). This is an open access article under the CC BY-NC-ND license (http://creativecommons.org/licenses/by-nc-nd/4.0/) area. Later, the airplane location was known while the search area is widened. It was reported by local news, search and rescue team sotted an airplane destroyed off the coast of Kalimantan on December $30^{\text {th }}$ 2014. Later, an airplane-like shadow was spotted at the sea in the search area where the parts and the airplane destroy was discovered.

All airplanes mentioned was equipped with a flight recorder which is known as the black boxan electronic recording device which serves the purpose of providing the information for the aviation accident and incident [3]. The accidents have indicated of the urgent need in developing the airplane tracking systems to prevent similar accident going in the future.

The airplane has lost contact while it was operating, thus, the airplane tracking system installed was untraceable in some condition. From the accidents, it was learned that the airplane missing in the middle of ocean is more difficult to be discovered as compared to the airplane crashed onto the ground. In the sea, the airplane could possibly go into the deep of the sea and the underwater locator beacon of the black box could not transmit the signal effectively.

A proposed method for airplane tracking system is explained in this paper.

The paper is organized as follows chapter II describes the existing system and chapter III describes proposed system

\section{EXISTING METHODOLOGY}

The existing system is named as "Black Box". It is a flight recorder which mainly consists of two parts. They are named as Cockpit Voice Recorder (CVR) and Flight Data Recorder (FDR). Though it is named as black box but it is of orange in colour. Black box is very necessary for airplane as is an electronic recording device that stores the recent history of an airplane for the last two hours. Black box is very helpful in finding the location of a crashed airplane during aviation accidents and it will send some beacon signals to find it. Alex and Yap Wei proposed existing airplane tracking system is lacks when airplane is dipped with water. This paper explains an airplane tracking system that able to track the airplane in the real time. The information of the location collected is presented on a web-based GUI. The proposed system is meant to be used as standalone tracker that is able to keep track on the airplane and improves the search time and rescue rate. This system is also designed to overcome the lack of airplane tracking capability [4].

Watthana wisuth et al proposed that wireless black box was developed for accidental surveillance. The system include components of microcontroller, motion sensor, GPS and GSM module, rf transmitter. At the time of accident, the RF transmitter will send message and gps link indicates the location of accident to family member, nearest hospital and emergency medical service. The motion sensors are used to determine fall or accident in real-time.

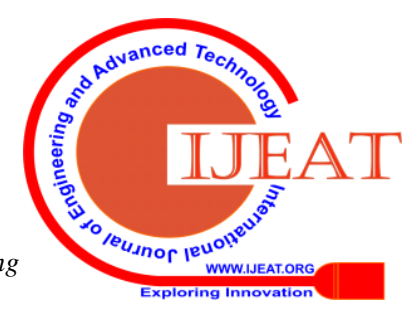




\section{A Smart Eye for the Lost Aeroplane}

The module is very small and easy to install at vehicle. The module had tested in real time by using bicycles. The results of that shows it can detect motion fall with high accuracy [5].

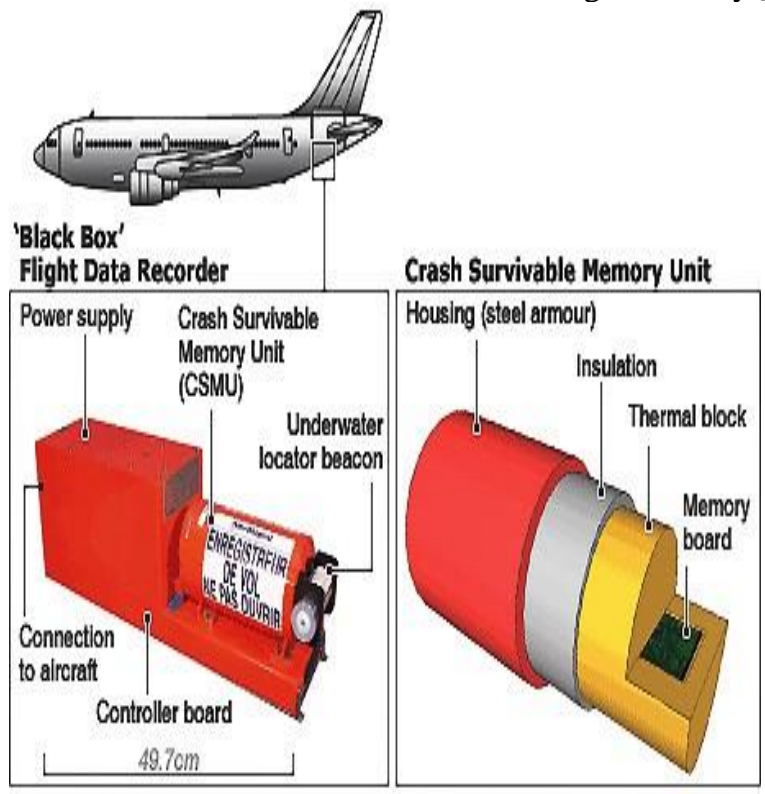

Fig. 1 Black box description

\section{PROPOSED METHODOLOGY}

The main aim of this proposed method to find the airplane very easily after the crash in the sea. It is completely different from black box, this module will be ejected whenever the plane is dipped into the water. The inner module will be ejected whenever it reaches the angle and vibration conditions of abnormal airplane. The inner module consists of GPS signals; it will always transmits the signal to the nearest receivers. It consists of heavy intensity flickering lights which are used to find easily during night.

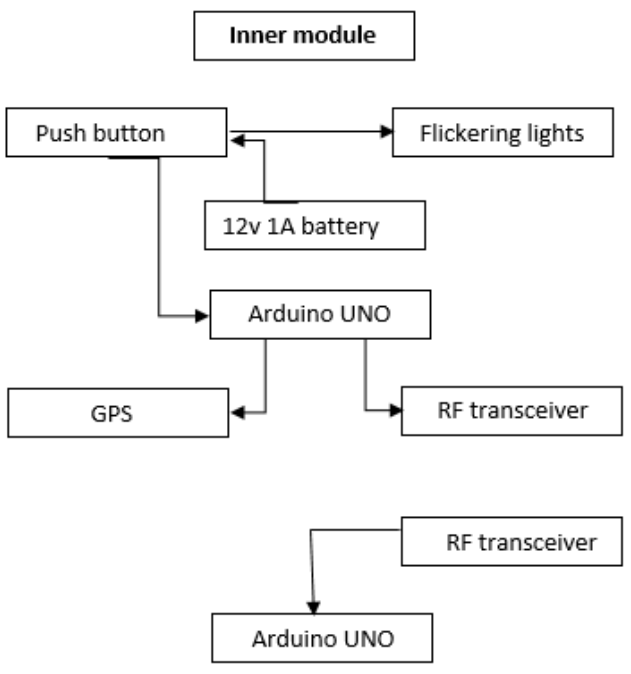

Fig 2. Outer Module block diagram

\section{HARDWARE REQUIREMENTS}

The proposed method requires the following hardware components-

1. Arduino Uno $\times 2$ and Nano $\times 1$

2. GPS Neo-6m

3. LoRa Transceivers $\times 2$

4. MPU6050

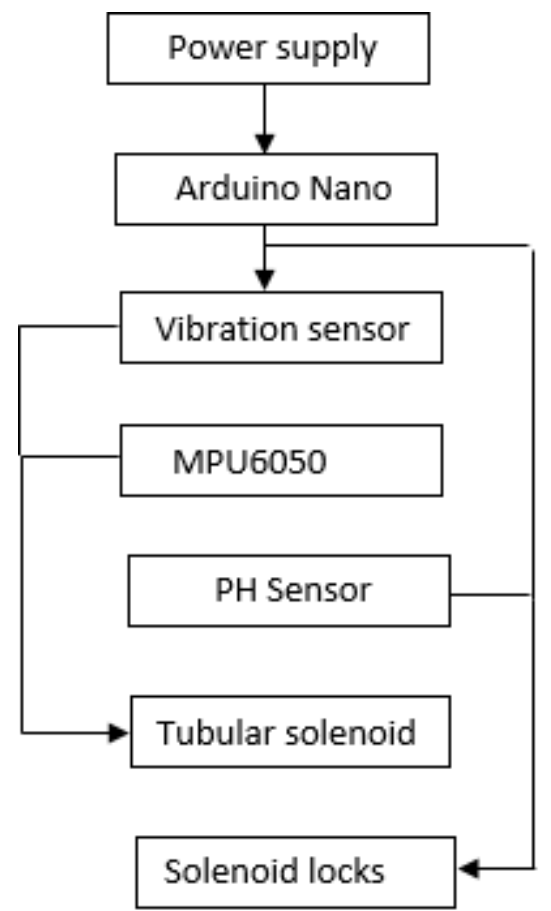

Fig 3. Inner module Block diagram

5. Vibration sensor

6. PH Sensor

7. Solenoids

8. Relays and push switches

9. Flickering lights

\section{A.Arduino}

The module requires a serial receiver pin, a serial transmitter pin, digital output pin and along with analog input pin. The microcontroller should be able to receive the GPS data. The GPS data able to transmit through the LoRa [6]. To do these operations, it requires one low power consumption of microcontroller. Here, Arduino has these requirements with Atmel ATmega328P microcontroller [7] of the Arduino Uno development board. The microcontroller taken due to the Arduino software has a serial monitor for the serial transmission of the connected development board and, its cost is cheaper than the other branded microcontrollers. It has EEPROM which can store the entire programming source code.

\section{B. GPS Neo-6m}

The GPS Neo-6m used by the Alex teohJit Ong and Yap Chee Wei [4] explained that it needs typical voltage of -0.5 to $3.6 \mathrm{v}$, acquisition current supply of $47 \mathrm{~mA}$, tracking current supply of 11 to $39 \mathrm{~mA}$, acquisition sensitivity of $-147 \mathrm{dBm}$, tracking sensitivity of $-160 \mathrm{dBm}$, position accuracy of $2.5 \mathrm{~m}$, update rate of $1 \mathrm{~Hz}$, Altitude limit of $50,000 \mathrm{~m}$, Baud rate of 4800/9600/38400/57600 bps, battery pack up along with external antenna with USART SPI interface [8]. The GPS neo selected due to these features with less cost and small module. The only drawback of this module is, it will work only in open sky along with less sensitivity compared to other GPS modules. 
The GPS receiver and transmit pins connected to the Arduino digital pins and VCC to Arduino 5v and ground to Arduino ground. The GPS module has 3.3 voltage regulator and battery pack up. As the battery gets charged automatically as given the programming for NMEA sentences, it will send the data to the serial ports of the Arduino Uno.

\section{C.LoRa E32 433T30D}

LoRa is the platform for long distance communication with log term battery performance. From the Ebyte of user manual [9] clearly explained about the E32-TTL-1W has IC SX1278, frequency of 410 - 440Mhz (default 433Mhz), power transmission of $21 \sim 30 \mathrm{dBm}$, distance of $8000 \mathrm{~m}$ [10] with UART interface. In research found that it could not transmits the data in any longer interference. It needs an open and clear without any obstacles, with maximum power, $5 \mathrm{dBi}$ antenna gain, height of $2 \mathrm{~m}$, and air data rate of 2.kbs. The LoRa E32TTL-1W SX1278 chip [11] is selected because of these above features, which is the best module compare to other RF modules with respective to best price.

The LoRa E32 433T30D receiver and transmit pins are connected to the serial ports of the Arduino, it receives the data from the Arduino and transmits to the receiver part of the LoRa and displays in serial monitor. After decoding the NMEA sentences the following fig 4 shows full details of the location.

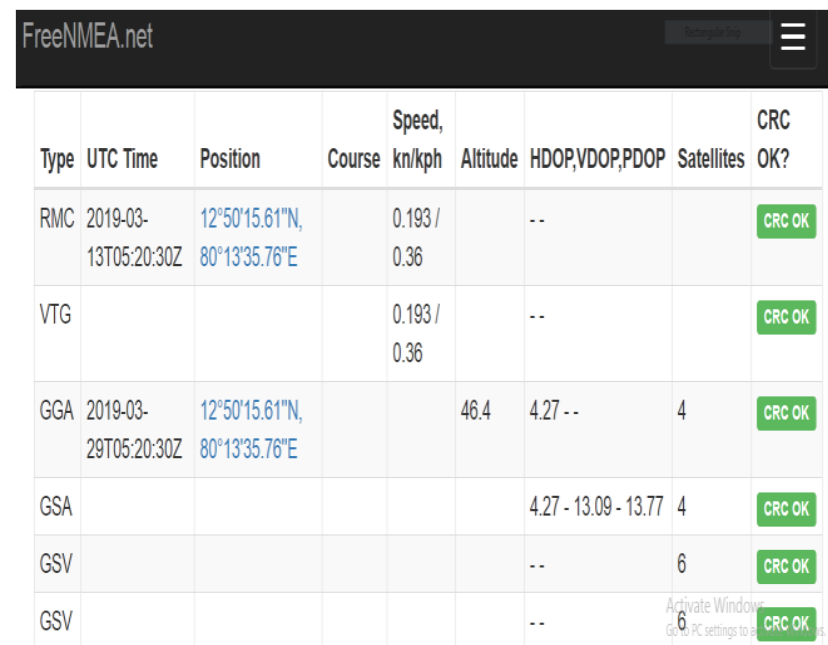

Fig 4. NMEA decoder website results

PU6050

The MPU6050 is a motion sensor, from the online tutorial manual [13], explains that, it has 6 axis which means of 3 -axis gyro and 3-axis accelerometer. The MPU pins of SDA and SCL are connected to the analog pins of Arduino 4, 5 and interrupt pin is connected to the digital pin 2 of Arduino. The raw data getting from the sensor is decoded by the program which is dumped into the Arduino microcontroller.

The MPU6050 used in this paper, whenever the airplane getting into the tilt angle or more than 110 degrees of the normal plane the tubular stroke solenoid pushes the push button of inner module to turn on the power supply as well as GPS will get started receiving data from there itself.

\section{D.Vibration sensor}

The SW-420 vibration sensor, from the Seed wiki [14], clearly explains about the sensor that measures the number of vibrations. This sensor able to adjust the sensitivity. There are

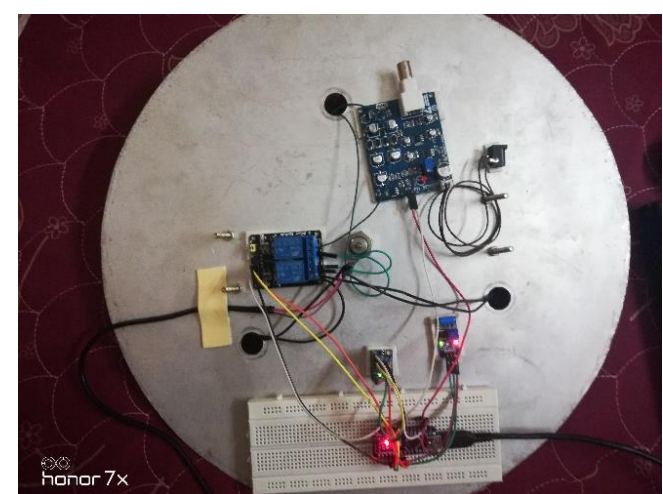

Fig 5. Outer module sensors circuit part

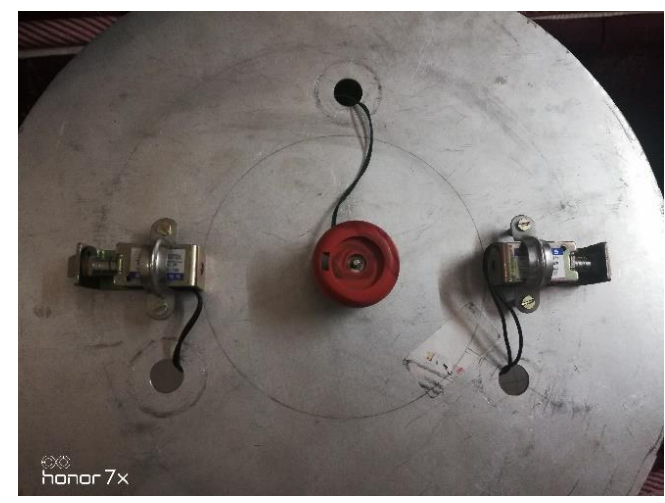

Fig 6. Solenoid ejecting part.

only 3 pins, one digital pin, one VCC and one ground. It supports the voltage of 3 to $5 \mathrm{~V}$

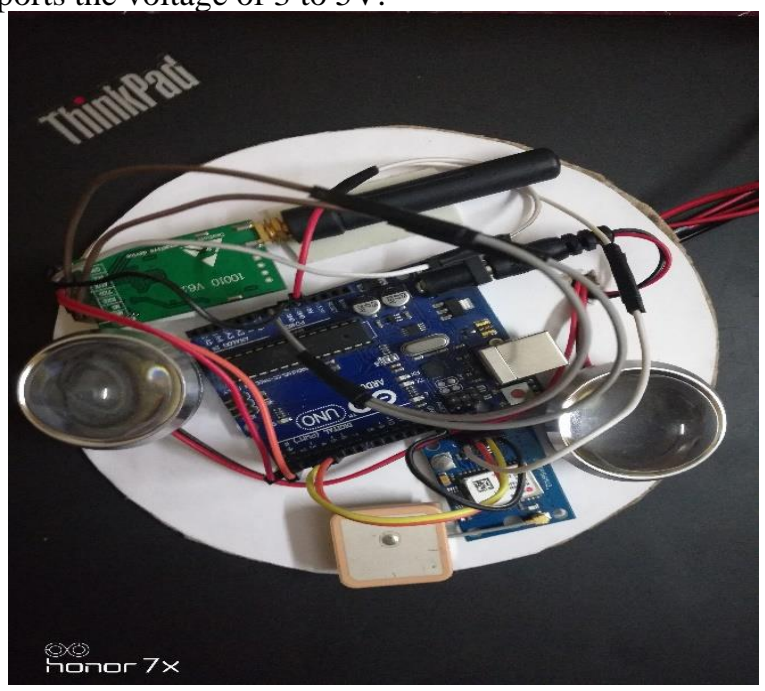

Fig 7. Inner module GPS along with LoRa transceivers part

This sensor selected is used to find the vibrations per second. While the number of vibrations per milli second is greater than the normal plane of vibration, is programmed in Arduino to turn ON the relay switch to push the solenoid. Not only the motion condition, this is the second condition to turn on the GPS.

\section{E.PH sensor}

From the website of the robocraze [15], explains clearly about the sensor along with the calibrated source code for the $\mathrm{pH}$ sensor [16]. This sensor has one probe to connect glass electrode. 


\section{A Smart Eye for the Lost Aeroplane}

The sensor has 3 pins one is analog data pin, one is $9 \mathrm{v}$ vcc input pin and another one is ground.

This sensor selected in this paper, whenever the flight get dipped into the sea, as programmed in the Arduino operates the second relay switch and turn on the solenoid locks to eject the inner module from the plane.

\section{F. Flickering lights}

These are very high intensity of led strobe lights [17] with IC555 which used to flicker or blink the multiple led. This lights emits red colour which indicated emergency.

This lights used in this paper, whenever the power supply of inner module is turned ON through push switch, lights automatically starts the flickering. Mostly, during night times through these lights can find the lost airplane.

\section{RESULTS AND DISCUSSION}

This paper proposes a system design for the tracking and monitoring of airplane by using the Long Range technology (known as LoRa). The proposed design is shown in Figure 1 and Figure 2. The inner module consists of the LoRa Shield Wireless, Arduino Uno board, GPS sensor and Wi-Fi module which are assembled in a microcontroller. This module is kept in an case such that what won't enter into it. The inner module will be ejected whenever it reaches the angle and vibration conditions of abnormal airplane. The inner module consists of GPS signals; it will always transmit the signal to the nearest receivers. It consists of heavy intensity flickering lights which are used to find easily during night. Lora receives the data from the Arduino and transmits to the receiver part of the LoRa which is then displayed in a serial monitor. After decoding the NMEA sentences the following figure 4 shows full details of the location.

The paper may affect the social aspect by developing the tracking effort. If an airplane installed with this type of technique system, whenever the crash happens, the relatives and friends of the victims may be less depressed at waiting time of the searching flight. Since the tracking might be improved, more victims would be saved.

The prototype developed is designed by using latest sensors which is of small in size; less cost is required to build along with less space. This methodology reduces the tracking period leads to less human effort and reduces fuel required for the operation.

Since this module is light weight, minimum extra force is needed to fly in the sky. For this prototype no need the external power supply constantly.

\section{CONCLUSION}

The proposed model for tracking the missed aero plane was proposed in this paper. The prototype was developed and tested. The work is completed with the required hardware by using latest technology and software to solve the real lift problem by proposing a relevant solution. The reference of this paper and some internet articles justifies the proposal to develop the existing system along with proposed system. A further standard of work is required for testing in real time on airplane.

\section{REFERENCES}

1. Simon caldor, INDEPENDENT, MH370 Missing plane article, September 24 $4^{\text {th }}$ 2018. [Online] article available from: https://www.independent.co.uk/travel/news-and-advice/flight-mh370malaysia-airlines-plane-missing-boeing-777-kuala-lumpur-beijing-201 4-documentary-a8552686.html

2. Jessie Yeung,CNN. (2018) Searching for MH370 plane ends but mystery remains. [Online] article available from: https://edition.cnn.com/2018/05/29/asia/mh370-search-ends-intl/index. html

3. Flight Recorder, From Wikipedia, the free encyclopedia. [Online] article available from: https://en.wikipedia.org/wiki/Flight_recorder

4. Alex TeohJit Ong, Yap Chee Wei, Design and development of Aircraft tracking system, 2015, ISBN: 978-1-4673-9572-4, Pages: 117 - 122.

5. N. Watthanawisuth, T. Lomas, A. Tuantranont, Wireless black box using MEMS accelerometer and GPS tracking for accidental monitoring of vehicles, 2016, INSPECAccession Number: 12785728, Page s: $847-850$.

6. Wikipedia Atmega328 microcontroller, Feb 25 ${ }^{\text {th }} 2019$. [Online] Available from: https://en.wikipedia.org/wiki/ATmega328

7. Neena Susan Shaji, T. C. Subbulakshmi, ResingtonMascarenhas R., Black box on earth - flight data recording at server stations, 2018, Print ISSN: 2377-6927Page s: $400-404$.

8. U-blox Neo-6m GPS module, posted on March $20^{\text {th }} 2017$. [Online] Available from: http://wiki.sunfounder.cc/index.php?title=Ublox_NEO-6M_GPS_Mod ule

9. E32 433T30D User manual, Jan 22, 2018, [Online] Available from http://www.ebyte.com/en/downpdf.aspx\%3Fid\%3D132+\&cd=2\&hl=e n\&ct $=$ clnk\&gl $=$ in

10. E32 TTL-1W product. [Online] Available from: http://www.ebyte.com/en/product-view-news.aspx?id=108

11. Semtech technologies, sx1278 chip[Online] Available from: https://www.semtech.com/products/wireless-rf/lora-transceivers/sx127 8

12. Maker Pro: MPU6050,March 21, 2018,[Online] Available from:https://maker.pro/arduino/tutorial/how-to-interface-arduino-and-t he-mpu-6050-sensor

13. GPS NMEA sentences decoder website [Online] Available from: http://freenmea.net/decoder

14. Seed Wiki: SW-420(vibration sensor). [Online] Available from: http://wiki.seeedstudio.com/Grove-Vibration_Sensor_SW-420/

15. PH sensor kit and source code, Posted on Jul 28, 2018 [Online] Available from: https://www.robocraze.com/blog/ph-sensor-kit.html

16. $\mathrm{PH}$ sensor product. [Online] Available from: https://www.amazon.in/gp/product/B077QLH9QD/ref=ppx_yo_dt_b_a sin title o09 s00?ie=UTF8\&psc $=1$

17. Amazon: flickering strobe lights. [Online] Available from: https://www.amazon.in/gp/product/B07D5WHT8H/ref=ppx_yo_dt_b asin title o03 s00?ie=UTF8\&psc $=1$

18. Robu.in Solenoid locks. [Online] Available from:https://robu.in/product/dc-12v-1a-10mm-stroke-15n-force-open-f rame-type-solenoid-electric-door-lock-if-s0837dl/

19. Venkatraman A, Chitra P" Realtime implementation of RTOS based vehicle tracking system,Biosciences Biotechnology Research Asia, April 2015. Vol. 12(1), 237-241.

\section{AUTHORS PROFILE}

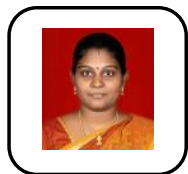

Dr. P.Chitra, is currently working as an Associate Professor in Sathyabama Institute of Science and Technology, Chennai, Department of ECE, She had received her doctorate in Sathyabama University in Sep, 2014. She had 15 years of teaching experience. She had published more than 25 papers in reputed journals and conferences. Her field of interest is Image processing, wireless sensor networks and soft computing tools.

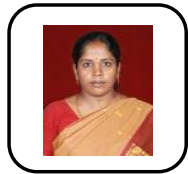

Dr. M.sumathi, received her Bachelor of Electronics and Communication Engineering Degree from Madras University and Master's Degree in Applied Electronics from Anna University, Chennai in 1992 and 2001 respectively. 
She taught a wide variety of courses at both undergraduate and postgraduate levels over a period of 25 years. She completed her Doctoral degree in RF CMOS VLSI and current areas of interest include analog/Mixed Signal VLSI design, RF/Microwaves, Optical Communication Systems, Biomedical Image Processing and VLSI signal processing/testing. She is currently working as Professor in Department ofElectronicsand Communication Engineering, SathyabamaInstitute of Science and Technology, Chennai, Tamilnadu, India. She had published more than 50 research papers in reputed Journals and Conference Proceedings.

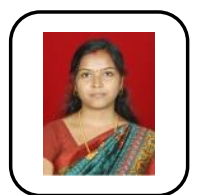

Ms. R. Sakthi prabha, received her Bachelor of Engineering in Electronics and communication in 2011. She received her Master of Engineering in Embedded system from Sathyabama Institute of Science and Technology in 2013. She is pursuing her Ph.D in Medical Image Processing at Sathyabama Institute of Science and Technology. Currently she also holds a faculty position as Assistant Professor,Department of ECE, Sathyabama Institute of Science and Technology, Chennai. Her main interests in research are Image processing, wireless sensor networks and soft computing tools

Dr. A.Sahaya Anselin Nisha, was born in 1981 in Tamilnadu. She received doctorate degree in the field of Microwaves in Sathyabama University in 2013, B.E Electronics and Communication Engineering in 2002 and M.E degree in Applied Electronics in 2006 with gold medal from Sathyabama University. She has more than 16 years teaching experience. At present she is working as a Associate Professor in Sathyabama Institute of Science and Technology, Chennai. She has published more than 20 papers International/National conferences. She has published a book named as, optical communication. Her field of interest is Electromagnetics, Microwaves and Antennas. 